\title{
A hermenêutica de Gaston Bachelard
}

Constança Marcondes Cesar ${ }^{1}$

\section{Meu encontro com a filosofia bachelardiana}

Conheci Bachelard através de sua epistemologia e depois descobri a poética. A epistemologia e seu contraponto na poética. Interessante porque comecei pelo Bachelard da epistemologia e depois voltei ao Bachelard da poética. Então é como se houvesse complementaridade entre ciência e poesia nesse autor, que depois de certo momento de sua vida, ele volta seu interesse para a psicanálise. É curioso porque o filósofo ainda não estava escrevendo sobre a epistemologia. Ele era o diretor na Sorbonne do Centro de Estudos da História das Ciências e, enquanto diretor desse centro, em 1945, ele já conhecia um pouco do Freud, conhecia a terapêutica de Freud e você vê isso quando ele usa o termo psicanálise para escrever a obra, A Psicanálise do fogo (1988), ele estava interessado nesse movimento e ao fim da guerra, em 1945, ele acolheu na Sorbonne o pessoal da linha freudiana, da psicanálise ortodoxa. Depois disso ele rompe, em 1947 com a psicanálise ortodoxa porque conhece a obra do Jung que fala de uma dimensão muito mais ampla, a terapia não é simplesmente eliminar o problema da repressão da sexualidade que é o problema do Freud, quer dizer, liberar as pessoas, mas é muito mais do que isso. Em Jung já aparecia a ideia de inconsciente coletivo, de uma exploração de possibilidades, tanto da razão quanto da emoção, Animus e Anima. Uma estrutura muito mais complexa do que Freud estava propondo e também entra em contato com surrealistas que faziam miséria, estavam explorando possibilidades outras que não tinham nada a ver com repressão mas tinha a ver, ao contrário, com exploração do imaginário e isso vai levar Bachelard, num primeiro momento, a fazer uma crítica da história das ciências. A epistemologia é a primeira parte de sua obra, a qual ele dá peso grande, mesmo depois desse encontro com Jung, mas ele conhece também Robert Desoille que Ihe diz uma coisa muito interessante; o problema do devaneio, o valor do devaneio, do imaginário. Então, tanto Jung quanto Desoille

\footnotetext{
${ }^{1}$ Universidade Federal de Sergipe, Aracajú - SE, cmarcondescesar@gmail.com 
exploravam o sonho acordado, o devaneio, o subsolo da psiquê humana com finalidades terapêuticas.

Contudo, em Bachelard o interesse não é terapêutico. O interesse é como trabalhar a dimensão do imaginário de modo a integrar isso numa promoção do humano. Então aquilo que aparece na primeira vertente epistemológica e ética favorece o diálogo entre cientistas, buscando aprimoramento permanente... já que a ciência não é um saber acabado, é um saber em evolução, saber que evolui por mutação, pelo diálogo, pela discussão, pelo debate e pelo sentido ético da existência que significa, nessa vertente epistemológica, expressar a máxima racionalidade possível em estado de abertura, e aí entra o filósofo do imaginário, para abrir o diálogo com a imaginação, com o sonho. Magnificar a vida nas fronteiras do sonho. Então Bachelard (1976) não está interessado em fazer terapia, quer dizer, o interesse dele por Jung e Desoille não é terapêutico. É, ao contrário, ver como se pode tornar complementares ciência e poesia fazendo com que o homem alcance uma expressão muito mais ampla e completa de si mesmo que é a busca de uma permanente autossuperação.

O que significa dizer que o diálogo entre cientistas é um diálogo permanente e sempre inacabado, tanto no âmbito da poética porque o objetivo de Bachelard vai ser, numa certa altura, tornar complementares aqueles eixos que eram antagônicos, de um lado a poesia, de outro lado, a ciência. Tornar complementares ciência e poesia visando um aprimoramento do homem, visando uma expressão cada vez mais alta. Isso aparece na Psicanálise do Fogo (1988), na Chama de uma vela (1975) e também em outra obra interessantíssima Direito de sonhar (1973). Nós temos o direito de sonhar. Esse sonho significa que devemos procurar uma contínua autossuperação, quer dizer, há possibilidade de um progresso infinito, inacabado que torne complementares ciência e poesia. Ou seja, essa busca de complementaridade entre ciência e poesia é que nos leva a ver que a hermenêutica de Bachelard é uma teoria que busca esclarecer o significado da vida humana através do exame crítico da evolução histórica das ciências e da constituição de uma poética e de uma ética. Certamente, esta é a obra fundamental de Bachelard. A finalidade do saber tanto científico quanto poético é o de levar o homem a realizar suas dimensões mais altas. Há um progresso em direção ao espírito, em direção a um aprofundamento de si mesmo, à realização de uma plenitude que é sempre inacabada, mas sempre tendendo a uma ascensão que ele diz de maneira muito bonita na Psicanálise do Fogo 
ou Fragmentos de uma poética do Fogo (1988): a tarefa do homem é buscar uma autossuperação permanente. Abrir-se como árvores e flores à dimensão das alturas, à uma transcendência permanente de si mesmo, sempre inacabada, e sempre possível ir adiante. É sempre possível crescer.

A ciência também tem uma dimensão de diálogo, de caminhar em direção às alturas. A ciência também tem esse lado. O objetivo tanto da poesia quanto da ciência seria levar o homem a uma autossuperação, a uma superação permanente.

No caso da teoria do conhecimento que ele propõe, é uma continua revisão das teorias científicas para um aprimoramento permanente. No caso da poética é uma transcendência permanente, um superar-se permanentemente. Caminhar em direção a uma autossuperação. A ideia de superação, tanto através de crítica e diálogo contínuo dos cientistas que os levam a formular teorias cada vez mais precisas, teorias que levam o homem a ascender no plano do conhecimento, a poética também tem esse papel.

Bachelard chega a dizer que há um certo denominador comum na intuição científica e na intuição poética. Há algo de intuitivo, de busca de aprimoramento permanente que é o que a poética nos traz. Um abrir-nos na direção das alturas, assim como também o conhecimento científico pode nos abrir a uma dimensão cada vez mais verdadeira, a uma interpretação cada vez mais precisa. E isso é absolutamente inacabado. Há uma permanente possibilidade de superação tanto na ciência quanto na poesia, porque elas são complementares. Tudo o que o filósofo pode tentar é tornar os eixos da poesia e da ciência complementares entre si. Um permanente impulso na direção de um ser mais.

\section{A hermenêutica bachelardiana}

Hermenêutica é uma palavra que vem do grego, hermeneuein que quer dizer interpretar, esclarecer, tornar compreensível; ainda em grego, hermeneutiké é a ciência, a técnica da interpretação de textos.

A hermenêutica de Bachelard é uma reflexão que busca tornar compreensível o significado da vida humana, através do exame da história das ciências e da constituição de uma poética e de uma ética.

Periódico Horizontes - USF - Itatiba, SP - Brasil - e021041 
A primeira abordagem, que enfoca a história das ciências, estuda a evolução do conhecimento científico, que se caracteriza pela descoberta progressiva da verdade, por um corracionalismo que associa a filosofia das ciências ao surgimento de um novo modelo de homem, o qual busca:

a) realização de um destino de conhecimento, que constitui sua felicidade;

b) implica, tal realização, em uma aproximação do cientista ao mistério da matéria, mediante o diálogo, a discussão com outros cientistas, a crítica recíproca buscando a verdade, a fidelidade à verdade.

A segunda implicação da hermenêutica bachelardiana mostra que o processo do conhecimento visa expressar um impulso espiritual, que considera complementares os eixos da poesia e da ciência, porque na criação científica de teorias há uma dimensão intuitiva, próxima da poesia.

Para nosso filósofo, o homem criador é alguém que, através da razão, científica ou poética, alcança a felicidade moral, realizando, na sua existência, verdade e transcendências, isto é, contínua autossuperação, em direção a um ser-mais, a um saber melhor.

A hermenêutica de Bachelard trata de esclarecer a busca da plenitude da vida, da realização do ser. Revela, assim, a felicidade que a vida criadora traz ao homem.

Nosso pensador nasceu na França, em 1864, em Bar-sur-Aube e faleceu em Paris, em 1962.

Em Paris manteve contato com os surrealistas e com o movimento psicanalítico. Conhecia a obra de Freud, mas desde 1942 se afastou, de modo crescente, da psicanálise ortodoxa. Apesar disso, recebeu, no Instituto de História das Ciências, do qual era diretor, em 1945, psicanalistas como Marie Bonaparte, que tinham sido proibidos de ensinar pelos nazistas, na França ocupada. Mas em 1945 rompeu com os psicanalistas ortodoxos e conheceu, em Paris, os surrealistas e se se aproximou da obra de Jung.

É a Jung, como a Robert Desoille, que Bachelard recorre, para se referir ao devaneio que abre o homem ao futuro, exposto na Poética do Espaço (1961) e na Poética do Devaneio (1974). Nessas obras, o pensador examina a imaginação dinâmica, entendida como o sonho da vontade - que realiza a unidade do ser: a unidade do sonho e do pensamento, superando a angústia de viver e abrindo o homem à vida criadora. 
A hermenêutica de Bachelard estuda os símbolos da transcendência, isto é, aqueles símbolos que levam o homem "a magnificar a vida nos fulgores do sonho", como ele assinala nos Fragmentos de uma poética do fogo. É a figura mítica da Fênix que Bachelard (1988) se refere, para interpretá-la como símbolo da poesia, da metamorfose da palavra, que nos leva a sonhar, a instituir um mundo, "na incandescência da imaginação", abrindo-nos " à dimensão das alturas", como ele afirma na obra, A chama de uma candeia.

A filosofia poética de Bachelard mostra o homem como um ser caracterizado pelas metamorfoses, em busca de sua plenificação.

Em outras palavras, para o filósofo, a hermenêutica é a decifração da linguagem da poesia e do devaneio, que revelam ao homem a finalidade do seu viver, transcender-se em direção a um ser - mais: "abrir-se, como as árvores e as flores, às Alturas [à luz] - uma Altura que tem a dignidade do sagrado" (BACHELARD, 1975, p.72) ${ }^{2}$, diz ele na obra $A$ chama de uma candeia.

O tema do fogo, entendido como metáfora da vida do espírito, aparece em diversos textos de Bachelard: A chama de uma candeia (1975), A Psicanálise do Fogo (1938), Fragmentos de uma poética do fogo (1988).

Essa hermenêutica tem implicações importantes: primeiro, a proposição de uma ontologia - do grego ontos e logos, estudo do ser - no caso, do ser humano - tratando de decifrar o significado do seu viver. E, em seguida, a proposição de uma ética - do grego ethos, comportamento segundo padrões morais, que caracteriza essencialmente o ser humano.

Bachelard conhecia a obra de Jung. Mas não é um terapeuta junguiano. Enquanto Jung, por exemplo, se atinha à proposição de um inconsciente coletivo, referido à humanidade, Bachelard propôs a noção de um inconsciente cósmico, que vincula estreitamente "a alma do homem à alma do mundo".

Um dos autores mais importantes ao qual Bachelard (1976) recorreu, foi seu amigo, Robert Desoille, o qual desenvolveu, como terapeuta, a técnica do "sonho acordado" (rêve éveillé), que visava a exploração do subconsciente e a ampliação do campo da consciência de seus pacientes. Sua técnica implicava relaxamento muscular, o devaneio orientado mediante a utilização de imagens de ascensão e o retorno gradual ao estado de consciência normal. 0

\footnotetext{
2 "nous devons nous ouvrir sans réserve à la dimension de la Hauteur — une Hauteur qui reçoit la dignité du sacré" (BACHELARD, 1975, p.72).
}

Periódico Horizontes - USF - Itatiba, SP - Brasil - e021041 
Objetivo da técnica era tornar a vida do paciente melhor, proporcionando calma e bem-estar.

Em O ar e os sonhos, Bachelard (1976) se refere aos trabalhos de Desoille como "ajuda preciosa" para o desenvolvimento de sua teoria da imaginação, que tinha por objetivo a expansão da consciência.

Desoille desenvolveu um estudo do "sonho acordado" e de sua utilização em psicoterapia. Como isso repercutiu em Bachelard? Como exame da imaginação dinâmica, entendida por ele como o sonho da vontade, que realiza a unidade do ser: a unidade do sonho e do pensamento, que leva o homem a superar a angústia e abrir-se a uma vida criadora.

Nos trabalhos de Bachelard o exame do papel da imaginação na vida humana dá-se no horizonte de uma ontologia e mostra laços estreitos com uma ética, que visa segundo nosso pensador, favorecer a promoção do ser, a sublimação feliz.

A perspectiva de Bachelard (1976) faz entrever, ainda, possíveis pontos de analogia entre seus trabalhos, os de Desoille e os de Jung, referentes à descrição da estrutura da psiquê e ao papel da imaginação ativa.

A hermenêutica de Bachelard (1988) examina os símbolos da transcendência, isto é, aqueles que levam "a magnificar a vida nos fulgores do sonho" como ele afirma nos Fragmentos de uma Poética do Fogo, como já assinalamos. É à figura mítica da Fênix que ele se refere, para interpretá-la como símbolo da poesia - entendida esta como metamorfose da palavra, que nos leva a instituir um mundo "na incandescência da imaginação".

Bachelard, inspirado nas técnicas de Desoille, indicou o papel da imaginação na vida humana:

a) transmutar as imagens provindas da percepção;

b) abrir o sujeito a novas formas de existir;

c) provocar vivacidade, aspiração ao novo, à viagem imaginária - emblema do percurso do real ao imaginário.

A liberdade, a expansão da consciência assim obtidas são, para Bachelard estreitamente ligadas a uma ética, à atividade espiritual que se encontra na poesia - levando o homem a transcender-se.

Não por acaso, os últimos escritos de Desoille foram dedicados a Bachelard: ambos esboçaram uma antropologia e uma ética, que têm como ponto axial a busca da ampliação da 


\section{HSE HORIZON TES}

consciência, equilibrando as forças opostas presentes na psique. Desoille, com fins terapêuticos; Bachelard, com finalidade ética.

Para Bachelard, a decifração de si é condição da compreensão de si, do mundo e do outro. Para ele o percurso em direção a si é desdobrado em um percurso que conduz ao conhecimento do outro e à meditação sobre a vida boa.

A apropriação e reformulação dos conceitos e contribuições de Jung e de Desoille foram caminhos que levaram Bachelard a uma reformulação das noções de homem, de razão, de saber, de interpretação da obra de arte e à proposição de uma ética, fundada na busca da felicidade, favorecida por uma abertura a um ser-mais, à vida criadora.

A hermenêutica de Bachelard é fiel à tradição grega da palavra, esclarece, interpreta, torna compreensível o significado do homem e do seu saber.

\section{Referências}

BACHELARD, G. La psycahnalyse du feu. Paris: Galimard, 1938.

BACHELARD, G. La poétique de l'espace. Paris: Les Presses universitaires de France, 1961.

BACHELARD, G. Le droit de rêver. 3. ed. Paris: PUF, 1973.

BACHELARD, G. La poétique de la rêverie. 6. ed. Paris: PUF, 1974.

BACHELARD, G. La flamme d'une chandelle. 5. ed. Paris: PUF, 1975.

BACHELARD, G. L'air et les songes: essai su la imagination du mouvement. 10. ed. Paris: José Corti, 1976.

BACHELARD, G. Fragments d'une poétique du feu: établissement du texte, avant-propos et notes par Suzanne Bachelard. Paris: Les Presses universitaires de France, 1988. 